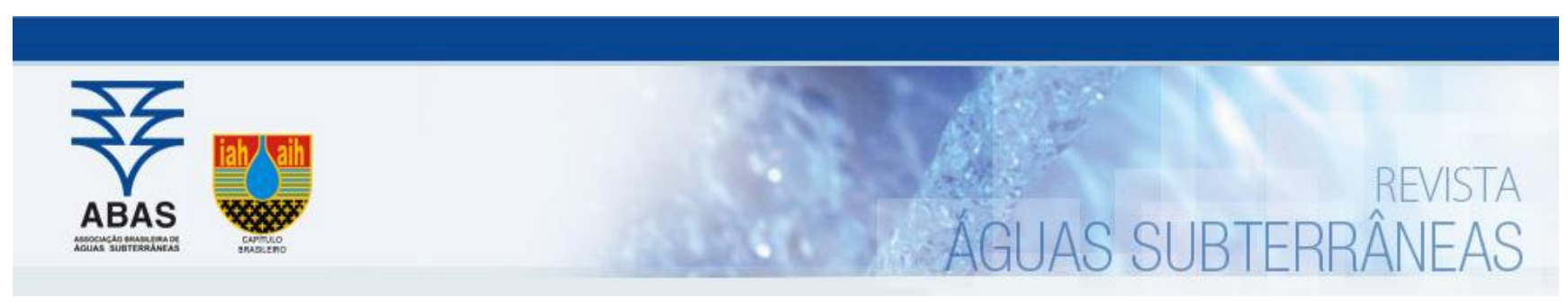

Artigos

\title{
A utilização do Ground Penetrating Radar (GPR) na definição de penetração de cunha salina e no monitoramento do nível freático em praia estuarina amazônica
}

\author{
The use of Ground Penetrating Radar (GPR) in the definition of salt wedge \\ penetration and groundwater monitoring in the estuarine Amazonian beach
}

\author{
Karolina Almeida Correia1; Marcos Welby Correa da Silva1; Amilcar Carvalho Mendes²; Artur Gustavo Oliveira de Miranda²; \\ Estanislau Luczynsky; Ivson Roberto Viana da Cunha ${ }^{\square}$
}

1 Universidade Federal do Pará (UFPA), Belém, PA

2 Museu Paraense Emilio Goeldi, Belém, PA

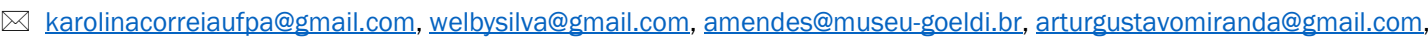
stasnis@yahoo.com, ivsonviana.42@gmail.com

\begin{tabular}{|c|c|}
\hline & Resumo \\
\hline $\begin{array}{l}\text { Palavras-chave: } \\
\text { GPR. } \\
\text { Cunha salina. } \\
\text { Praia estuarina. } \\
\text { Nível freático. } \\
\text { Amazônia. }\end{array}$ & $\begin{array}{l}\text { A identificação do nível freático foi bastante clara, revelando uma transição entre zona não saturada e zona saturada } \\
\text { bem definida. Os perfis de GPR mostraram que o topo do nível freático é registrado como um refletor horizontal forte, } \\
\text { mergulhando em direção ao mar. O topo do nível freático na zona de pós-praia está localizado em aproximadamente } \\
1 \text { metro de profundidade, no período chuvoso (março), tornando-se mais profundo na zona intermarés. No período de } \\
\text { estiagem (novembro), o topo da superfície do nível sofre rebaixamento, variando de } 1,9 \text { metros na zona supramarés, } \\
\text { a e } 2 \text { metros na zona intermarés. A umidade do solo e, sobretudo, a presença de sal nos sedimentos praiais tiveram } \\
\text { forte influência nos sinais da reflexão, mudando a constante dielétrica dos sedimentos e, consequentemente, crian- } \\
\text { do zonas de atenuação de sinais, permitindo, dessa forma, mapear a cunha salina em subsuperfície durante o } \\
\text { período de estiagem. Contudo, é recomendado um estudo geofísico utilizando outros métodos, buscando melhores } \\
\text { resultados do ponto de vista hidrogeológico. }\end{array}$ \\
\hline
\end{tabular}

Keywords:

GPR.

Salt wedge estuarine beach. Groundwater.

Amazon.

Revisado por pares.

Recebido em: 12/01/2018. Aprovado em: 17/02/2019.
The association of survey data with records obtained through the use of the Ground Penetrating Radar (GPR), taking into account the climatic seasonality, in Praia do Farol (Mosqueiro Island / Belém-PA), revealed the behavior of the water table and the record of the penetration of the salt wedge into subsurface in this estuarine environment. The identification of the water table was very clear, revealing a transition between unsaturated zone and well-defined saturated zone. The GPR profiles show that the level of the top of the water table is registered as a strong horizontal reflector, diving towards the sea. The top of the water table in the post-beach zone is located approximately 1 meter deep in the rainy season (March), becoming deeper in the intertidal zone. During the dry season (November), the top of the surface of the sheet undergoes deepening, ranging from 1.9 meters in the supramarine zone to 2 meters in the intertidal zone. The soil moisture and, above all, the presence of salt in the beach sediments had a strong influence on the reflection signals, changing the dielectric constant of the sediments and, consequently, creating zones of signal attenuation, thus allowing mapping of the salt wedge in subsurface during the dry season. However, a geophysical study is recommended using other methods, seeking better results from a hydrogeological point of view.

\section{INTRODUÇÃO}

As cidades litorâneas da região metropolitana de Belém-PA têm um alto tráfego de navios e possuem zonas portuárias com grande potencial a eventos envolvendo vazamento de derivados de hidrocarbonetos. Nesse contexto, o Ministério do Meio Ambiente definiu normas e medidas para elaboração de cartas de sensibilidade ambiental para desastres relacionados à petróleo e derivados na zona costeira e mari- nha, no intuito de prevenir e minimizar os impactos que o meio ambiente poderia sofrer com possiveis derramamentos de óleo.

A contaminação por derivados do petróleo em praias arenosas, que possivelmente irá atingir a zona freática, depende, dentre outros fatores, da permeabilidade do substrato, das propriedades granulométricas da areia e das características físicas do óleo (Davies \& Topping, 1995). 
Outra preocupação quanto a desastres com estes impactos seriam a contaminação de poços de água e do nível freático de famílias que habitam a área litorânea da região metropolitana de Belém. Ademais, nas áreas costeiras, a intrusão da cunha salina muitas vezes impossibilita a utilização da água subterrânea para consumo público, daí a necessidade de se determinar com precisão a interface da água doce/água salgada, com intuito de se preservar a qualidade desse recurso hídrico subterrâneo. Devido a esses riscos, o estudo e monitoramento do nível freático são de suma importância para que em caso de acidentes, as medidas necessárias sejam providenciadas pelos órgãos competentes.

A água subterrânea é a principal fonte de água potável na maioria dos países (Princewill et, al. 2016). Desta forma as populações residentes na costa dependem das águas subterrâneas costeiras para o abastecimento de água doce. Contudo o sal pode afetar adversamente a qualidade e quantidade deste recurso, resultado do processo da intrusão salina de forma natural. Este é considerado um dos mais extensos e importantes processos que degradam a qualidade da água, que é determinado através de valores de salinidade que caracterizam a água potável e a água usada em sistemas de irrigação, por níveis de salinidade (Hodlur et al. 2006, 2010; ; Demirel 2004; Sivan et al. 2005; Narayan et al. 2007; Rejani et al. 2008; Martınez et al. 2009; Adeoti et al. 2010; Zarroca et al. 2011; Guha, 2010; Caroti, et al. 2013; Erku, et al. 2014; Kumar et al. 2016).

Dentre as técnicas de possível aplicação para este tipo de monitoramento destaca-se o radar de penetração de solo (GPR), técnica geofísica baseada na reflexão de ondas eletromagnéticas de altas frequências $(10-1000 \mathrm{MHz})$ em descontinuidades presentes no subsolo. Some-se a isso o baixo custo operacional e a facilidade de processamento de dados.

Aplicações de GPR em ambientes costeiros estão diretamente relacionados com a fisiografia e geologia da região de investigação e têm sido realizadas ao longo da última década. Rossetti (2001) utilizou o método como ferramenta para caracterizar fácies e estratigrafia dos depósitos conhecidos informalmente como Sedimentos Pós-Barreiras, na região Bragantina no Estado do Pará, em que concluíram que a unidade correspondente aos Sedimentos Pós-Barreiras é mais variável faciologicamente do que inicialmente imaginado, incluindo depósitos eólicos (dunas costeiras), bem como depósitos de cordão litorâneo, planície de maré, canal e planície de maré lamosa. Sua análise se baseou na configuração das reflexões internas e a geometria destas reflexões nos radargramas.

Silva (2015) buscou a definição litoestratigráfica e geológica das unidades neógenas da Região do Salgado, utilizando como técnica o imageamento por GPR e correlacionando com dados sedimentológicos foi possível identificar litofácies, geometria de camadas e de estruturas de possível origem tectônica dos depósitos neógenos, carbonáticos e siliciclásticos relacionadas, respectivamente, às formações Pirabas e Barreiras, bem como sedimentos quaternários da unidade Pós-Barreiras, que constituem o preenchimento da Plataforma Bragantina.
Estes trabalhos mostram que a utilização do GPR como ferramenta para o imageamento de ambientes costeiros abre uma oportunidade de se adquirir informações de maneira ágil e com grande qualidade na definição de estruturas geológicas em ambiente sedimentar (Pereira, 2003).

Prospecção geofísica da transição água doce-salgada foi realizada com sucesso desde a década de 1950, mapeando a distribuição espacial da eletricidade específica resistividade do subsolo. Zonas de águas salinas ou salobras podem ser confiáveis detectado em terra por sonda de profundidade geoelétrica porque a resistividade elétrica em massa de sedimentos é essencialmente determinado pela resistividade elétrica do fluido poroso, que depende da concentração de íons ou do teor de sal. Sondagem geoelétrica e tomografia de resistividade elétrica (ERT) são ferramentas confiáveis para identificar zonas de intrusão de água salgada ou descarga de águas subterrâneas em um sentido qualitativo (Erkul,2014).

Estudos sobre como o nível freático varia de acordo com ambientes também tem ser tornado de extrema importância não só na avaliação de dispersão de contaminantes, mas, também, na determinação de gradientes hidráulicos, direção de fluxo, identificação de zonas de recarga e descarga e na interpretação de dados geoquímicos. 0 georadar se mostrou eficaz na detecção da zona do nível freático em tipos diferentes de regiões de levantamento.

Em ambientes estuarinos, Lani et al. (2005) fizeram estudos sobre dinâmica do nível freático no delta do rio Doce, verificando a eficiência deste método na análise do comportamento da profundidade da zona freática ao longo de um canal de drenagem.

Sendo assim, o uso da tecnologia do georadar consegue delinear aproximadamente a zona de capilaridade em que se encontra o nível freático, ou seja, há uma faixa de transição entre o meio insaturado e o meio saturado com água doce e é este fenômeno que será verificado com os resultados apresentados neste trabalho.

Em ambientes costeiros a análise conjunta de parâmetros geológicos e geofísicos vem sendo bastante utilizada devido ao alto grau de informação obtido a partir das interpretações correlacionadas. O GPR por sua vez é aplicado principalmente para a caracterização de ambientes deposicionais, pois com a análise de traços obtidas e observando a atenuação do sinal é possível definir e investigarníveis distintos de ambientes deposicionais (Leandro, 2018).

Investigações utilizando GPR já foram realizados para os mais variados fins em regiões de zonas praianas. Para investigações da espessura dos pacotes sedimentares, estruturas, migrações de linha de costas e monitoramento do nível freático (Bristow \& Jol, 2003; Giraud et, al. 2011).

Neste trabalho o método GPR foi aplicado com o objetivo de monitorar e identificar a zona freática em praia estuarina, além do estudo da possível entrada da cunha salina neste ambiente. 0 trabalho, associado (e.g. granulometria, permeabilidade), contribui para a compreensão da dinâmica de difusão de possíveis contaminações por hidrocarbonetos ao 
relacionar o ambiente em que ocorre a contaminação com as variações sazonais do nível freático.

\section{GEOLOGIA E HIDROGEOLOGIA DA ÁREA}

As unidades geológicas da região de Belém e adjacências são representadas pelas formações Pirabas, Barreiras e Sedimentos Pós-Barreiras. A deposição dessas unidades foi particularmente controlada pela formação e reativação de falhas normais e transcorrentes (Costa et al., 1996)

Com base em vários estudos, principalmente sedimentológicos e paleontológicos, Rossetti (2001) integralizou informações sobre estas formações e propôs uma divisão por sequência (Figura 1) para a região nordeste do Pará, que engloba a região de Belém.
São elas:

a) Sequência A: compreende a Formação Pirabas e a parte inferior da Formação Barreiras. A sequência representa a passagem gradual lateral $\mathrm{e}$ ascendente dos depósitos Pirabas para os sedimentos do Barreiras.

b) Sequência B: corresponde a parte intermediária e superior da Formação Barreiras.

c) Sequência C: representa os Sedimentos PósBarreiras.

Quase toda a superfície da ilha é composta por latossolos derivados dos lateritos. Porém, porções de areia quartzosas brancas (podzóis) surgem em meio a estes solos, provenientes de lixiviação “in loco” dos mesmos (Sá, 1969).

Figura 1- Sequências estratigráficas do Cenozóico (Paleogeno Superior - Neogeno) das plataformas Bragantina e Pará. A - Formação Pirabas e a parte inferior da Formação Barreiras; B - parte intermediária e superior da Formação Barreiras; C - Sedimentos Pós- Barreiras (Rossetti, 2001)

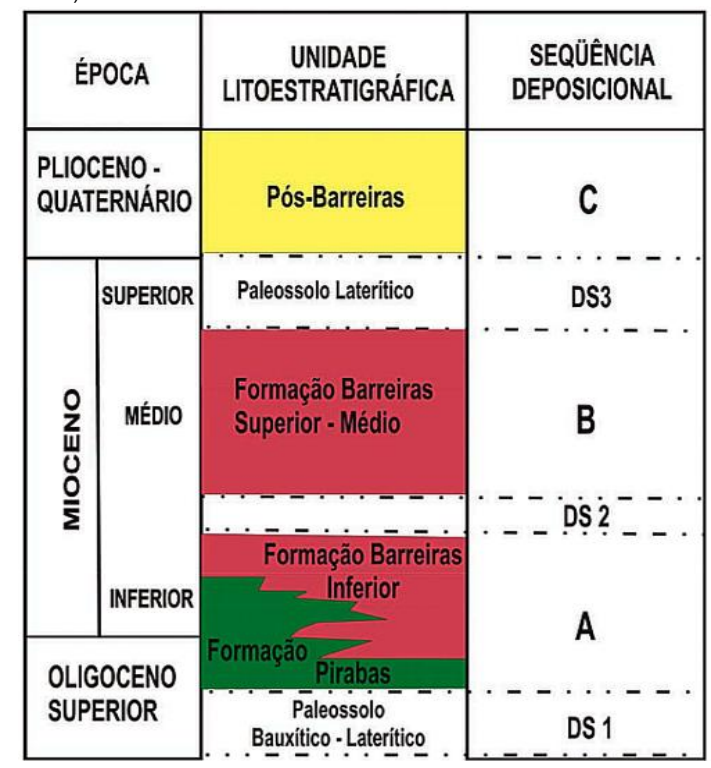

Essa é uma região sedimentar, onde a capacidade de armazenamento e circulação de água dependem da porosidade das rochas que compõem as formações Pirabas, Barreiras e coberturas detríticas lateríticas e aluvionares. A compartimentação hidrogeológica é composta de aquíferos intergranulares descontínuos, livres; intergranulares contínuos, livres e semiconfinados; intergranulares contínuos, livres e confinados (CPRM, 2001).

\section{LOCALIZAÇÃO DA REGIÃO DE ESTUDO}

A área de estudo corresponde à Praia do Farol, localizada na
Ilha de Mosqueiro, região metropolitana de Belém, estando, portanto, na zona de influência direta e indireta de atividades portuárias.

A llha de Mosqueiro (Figura 2) é um dos distritos da região metropolitana de Belém e está aproximadamente a $72 \mathrm{~km}$ do centro de Belém. 0 acesso se dá pelas rodovias BR-316 e PA-391. Mosqueiro possui uma área em torno de $223 \mathrm{~km}^{2}$ e é divida em bairros. O levantamento de GPR realizado na região fica situado no Bairro do Farol (Figura 2). 
Figura 2 - Mapa de localização do perfil de GPR

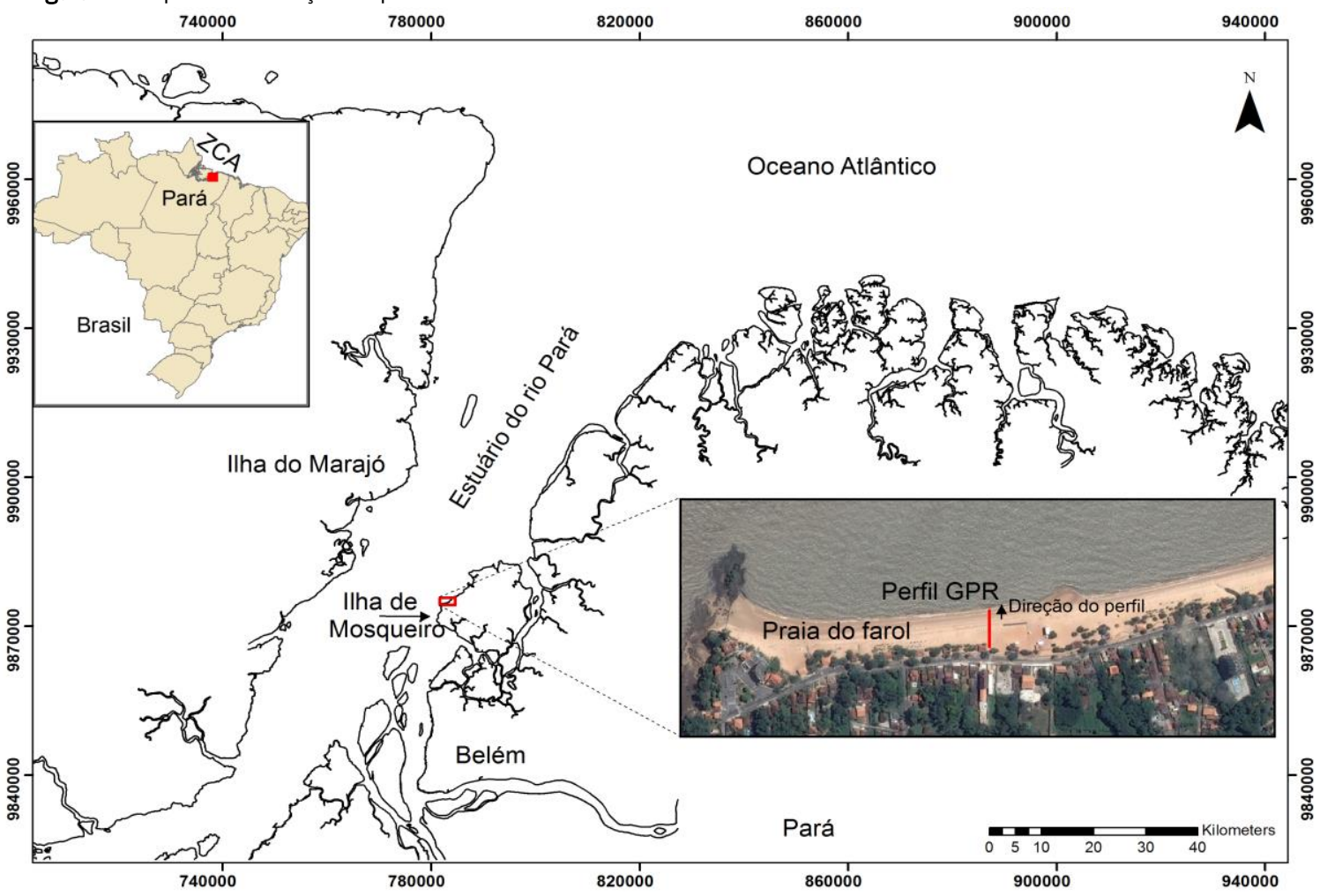

\section{MÉTODO E OPERAÇÕES DE CAMPO}

Foi utilizado o método de levantamento sísmico mediante utilização do Ground Penetrating Radar (GPR), fundamentado na propagação de ondas eletromagnéticas de altas frequências, na faixa de $10 \mathrm{MHz}$ a $1 \mathrm{GHz}$ (Davis \& Annan, 1989). 0 método GPR consiste na transmissão e reflexão de ondas EM a fim de exibir uma imagem de alta resolução do meio de investigação. Para adquirir dados de GPR, as antenas de radar foram colocadas sobre a superfície do solo e deslocadas ao longo de perfis perpendiculares à linha de costa, resultando em uma imagem baseada nas variações laterais das propriedades físicas dos materiais em do subsolo (Daniels,1996; Porsani,1999).

Do ponto de vista da teoria eletromagnética, faz-se necessário ter conhecimento das relações constitutivas do meio que determinam propriedades específicas dos materiais em subsuperfície, quais sejam: permissividade elétrica $(\varepsilon)$, condutividade elétrica $(\sigma)$ e permeabilidade magnética $(\mu)$.

A onda eletromagnética se propaga no vácuo com velocidade de 0.2997924583 m/ns. Em subsuperfície esta velocidade é reduzida, ocorrendo espalhamento e atenuação do sinal, fenômenos que dependem das propriedades geoelétricas do meio. Dentre essas três propriedades, apenas a condutividade elétrica e a permissividade elétrica controlam a velocidade. Assim, segundo Daniels (1996), a velocidade de propagação de onda eletromagnética é dada pela expressão:

$$
v=\frac{c}{\sqrt{\varepsilon_{T}}},
$$

em que $\varepsilon_{r}=\frac{\varepsilon}{\varepsilon_{0}}$, com $\varepsilon$ sendo a permissividade elétrica do meio e $\varepsilon_{0}=8.85 \cdot 10^{-12} \mathrm{~F} / \mathrm{m}$ é permissividade do vácuo.

Conhecer essas propriedades é importante para que haja melhor interpretação, pois, sabendo o tempo de trânsito entre o início e a chegada da onda refletida e a velocidade da propagação da onda eletromagnética no meio é possível estimar a profundidade em subsuperfície aproximada de refletores que sejam de interesse para a pesquisa de campo.

Tabela 1 - Parâmetros que governam o comportamento do sinal do georadar no meio

\begin{tabular}{ccc}
\hline Material & $\sigma(\mathrm{ms} / \mathrm{m})$ & $v(\mathrm{~m} / \mathrm{ns})$ \\
\hline Ar & 0 & 0.3 \\
Água Salgada & 3000 & 0.01 \\
Solo Arenoso Seco & 0.14 & 0.18 \\
Solo Arenoso Saturado & 6.9 & 0.06 \\
\hline
\end{tabular}

Para a coleta dos dados foi utilizado o equipamento TerraSIRch SIR System-3000 da GSSI (Geophysical Survey Systems, Inc.), com uma antena biestática blindada de $200 \mathrm{Mhz}$ (Figura 4 A). Esta frequência permitiu investigar profundida- des de até 7 m com um aceitável nível de ruído.

O método de aquisição de dados consistiu em executar perfis de reflexão, orientados perpendicularmente à linha de prea- 
mar. Na execução desses perfis, foi percorrida uma linha demarcada sobre o terreno (abrangendo os setores de supramaré e intermaré), deslocando as antenas do GPR ao longo desta linha, e executando leituras em pontos equidistantes (Figura 4B). Nos perfis adquiridos foi usada a configuração das antenas em modo common offset, ou seja, separação entre a antena transmissora e receptora constante.

Para a observação sazonal do nível freático foram realizadas medições de nível em poços de abastecimento dos estabelecimentos comerciais existentes nas praias (melhor e mais barato instrumento de observação do nível, porque as observações refletem perfeitamente a posição e oscilação reais do nível freático). Para a leitura da profundidade do nível freáti- co, foi utilizado o medidor de nível marca SoilControl, modelo WaterControl/ECP (cabo de 100m), equipamento elétrico que possui uma fita milimetrada de $10 \mathrm{~mm}$ de largura ligada a um sensor tipo elétrodo cromado, com ponta em tecnil, que, ao ser introduzido nos poços, emite um sinal sonoro quando atinge o nível d`água (Figura 5).

Os levantamentos geofísicos foram realizados no período de fevereiro, junho, setembro e novembro de 2015 e março de 2016. Durante a etapa de campo, todos os levantamentos foram realizados no mesmo ponto e levaram em consideração a sazonalidade, pois na região amazônica ocorre um período mais chuvoso (janeiro a abril) e um período menos chuvoso (setembro a dezembro) (Figura 6).

Figura 3 - Operações de Campo. A) Aparelho GPR utilizado nos levantamentos; B) Perfil de GPR realizado na praia do Farol
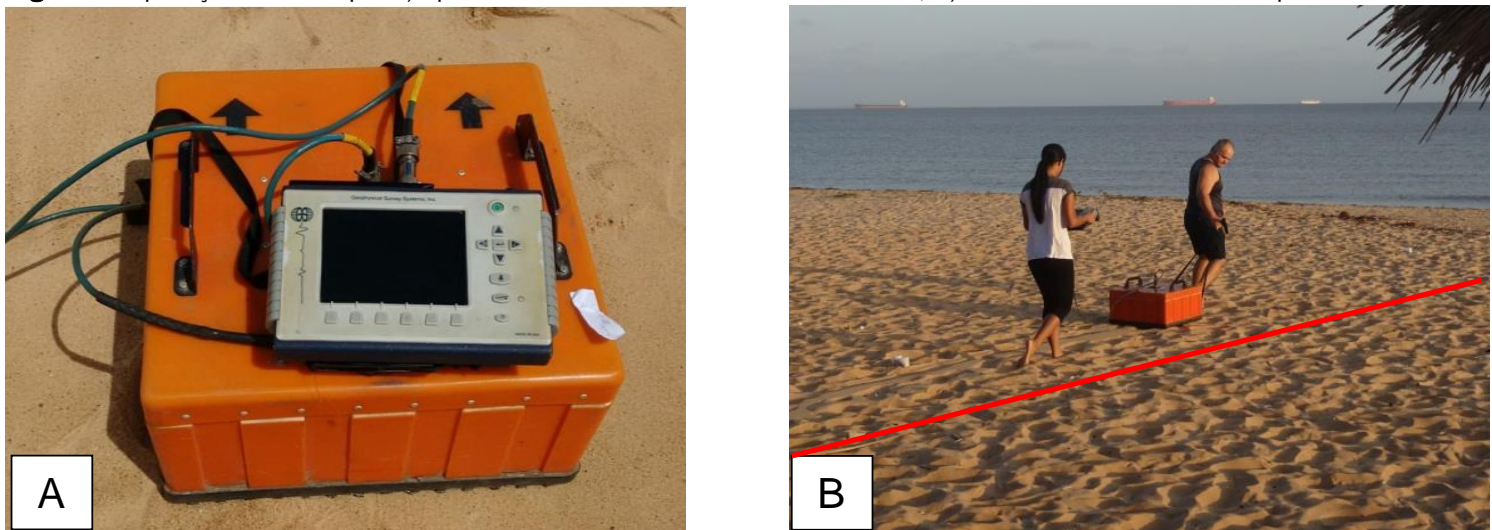

Figura 4 - Mensuração do nível do nível freático em poço de abastecimento mediante utilização do medidor eletrônico

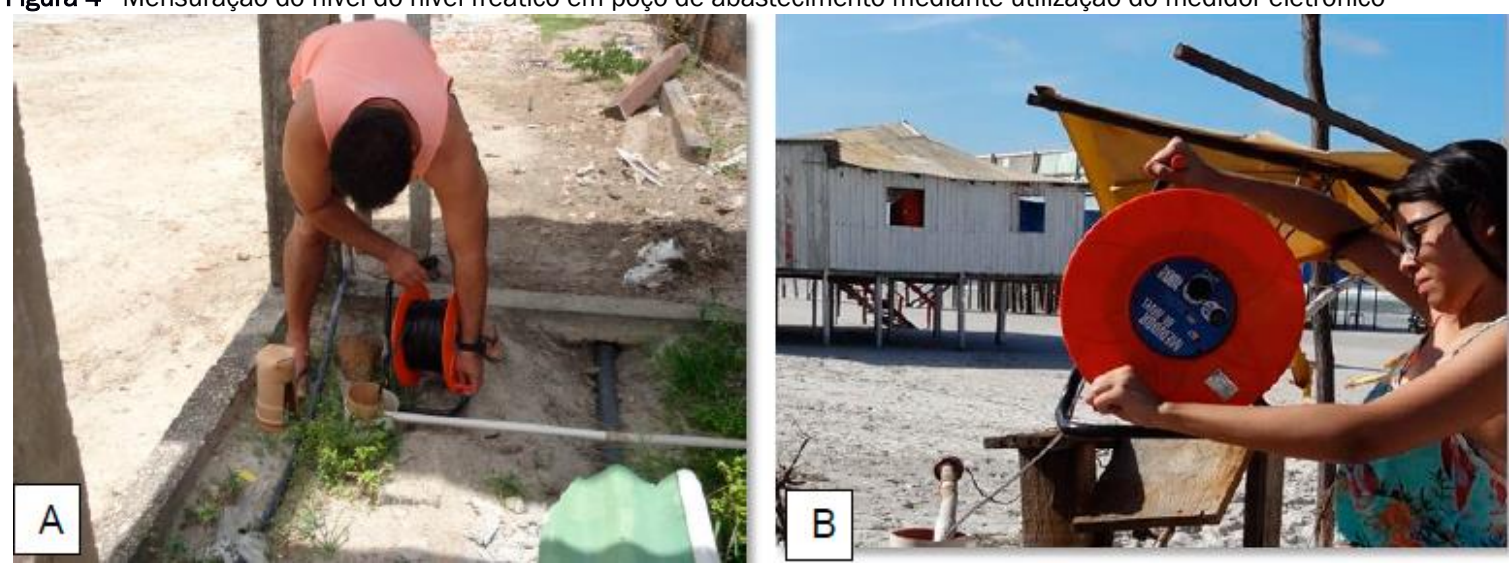




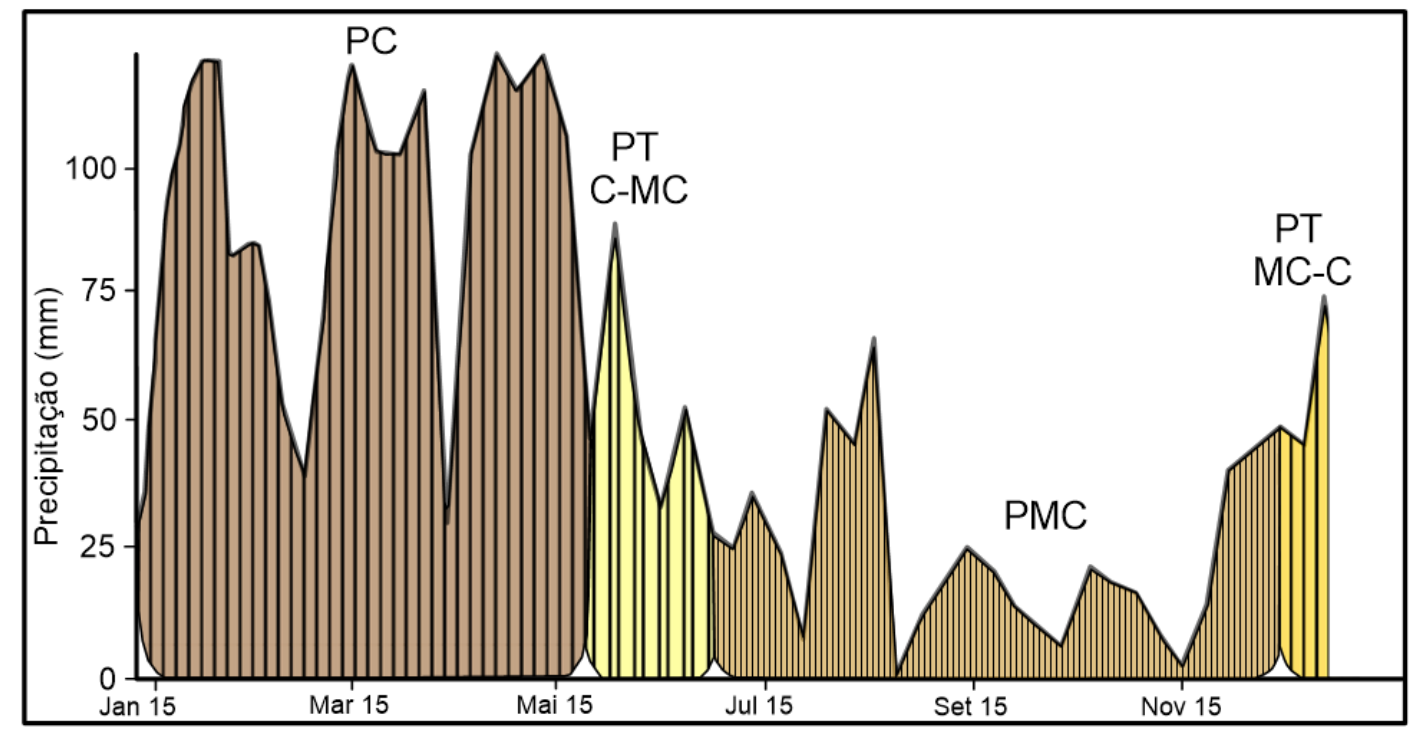

Legenda: Período chuvoso - PC; Período transicional - PT; Período menos chuvoso - PMC; Chuvoso - C; Menos chuvoso - MC.

Após as aquisições de GPR os dados foram processados no software Reflexw-Win7.0, seguindo a seguinte rotina de processamento:

1. Interpolação das marcas horizontais: que normaliza a escala horizontal do perfil coletado no modo tempo.

2. Correção estática (set time zero): elimina o efeito da onda direita e realiza a correção do tempo zero. Esse passo do processamento foi aplicado a fim de realizar o ajuste do tempo-nulo (tempo zero) com a profundidade nula e corrigir a topografia do terreno.

3. Filtros 1-D PassaBanda (Butterworth, Frequency): são filtros que ajudam a eliminar ruídos de baixa e alta frequência, melhorando significativamente a relação sinal/ruído, contribuindo para facilitar a identificação os alvos.

4. Dewow: pode eliminar uma boa parte das baixas frequências associadas a saturação do sistema de registro, devido as grandes amplitudes das ondas diretas no ar e no solo.

5. Background Removal: Este filtro foi utilizado para tentar eliminar o efeito de refletores horizontais que são comuns nos dados de GPR, e com a eliminação destes, torna-se mais visível os refletores inclinados e outros pontuais;

6. Filtro F-k: foi empregado para atenuar ruído de refletores inclinados e enfatizar os mergulhos procurados. Sua aplicação envolve a geração do fk-spectrum, o qual realiza uma transformada de Fourier dos dados do domínio do espaço para o domínio do número de onda (Furtado,2009).

A modelagem geofísica foi implementada utilizando o módulo de diferenças finitas no domínio do tempo -FDTD- do software Reflexw com intuito de verificar e validar à entrada da cunha salina em subsuperfície.

\subsection{Coleta de sedimentos intermarés e supramaré}

A coleta de sedimentos praias ocorreu na camada superficial ( $\pm 50 \mathrm{~cm}$ ) e ao longo dos perfis monitorados(Figura 6). Para essa coleta foi utilizada uma espátula e coletada uma quantidade em torno de $200 \mathrm{~g}$. As amostras foram devidamente etiquetadas e levadas para o Laboratório de Análises de Sedimentos e Solos do Museu Paraense Emílio Goeldi, onde foi realizada a preparação para análise granulométrica.

Além dos sedimentos superficiais foi amostrado o pacote sedimentar nos setores intermaré e pós-praia. Foi utilizado um amostrador à vibração, acoplado a tubo de alumínio. Testemunhos foram retirados para posterior análise granulométrica e descrição das estruturas sedimentares. Dada a dificuldade de penetração no pacote sedimentar arenoso, as coletas com tubos de alumínio não foram superiores a $2 \mathrm{~m}$. $\mathrm{Na}$ retirada dos tubos, esses foram serrados bem próximo ao topo da sequência amostrada.

Após a separação granulométrica por peneiramento foi extraída uma alíquota da classe granulométrica dominante, a qual foi disposta em uma lâmina reticulada, de fundo preto e fosco. Para a observação dos grãos, foi utilizada as frações de areia grossa $(500 \mathrm{~mm})$, onde foram observados grãos de quartzo, dada a sua ampla distribuição nos sedimentos praiais. Essa fração e areia foi disposta em lâmina reticulada, com fundo preto e fosco para análise em uma lupa binocular com iluminação por reflexão dirigida a $45^{\circ}$ e zoom óptico de $0,75 x$.

Em cada amostra foram observados 100 grãos. Evidentemente que a observação de um número maior de grãos ampliaria o rigor estatístico da análise, normalmente não conduz a melhoria significativa dos resultados. 
Figura 6 - Coleta de sedimentos superficiais

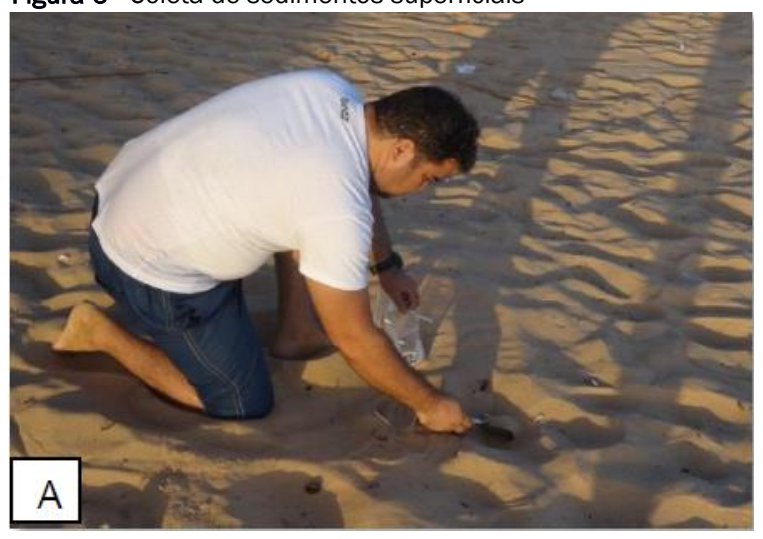

\section{APRESENTAÇÃO E DISCUSSÃO DOS RESULTADOS}

\subsection{Análise Granulométrica da praia do Farol}

A distribuição granulométrica dos sedimentos da praia do Farol evidencia a predominância de areia média, na zona de supramaré, com algumas frações finas encontradas em junho e setembro, e areia muito grossa no setor intermaré, sobretudo nos meses chuvosos (fevereiro e março), não havendo variações de classes granulométricas ao longo do ciclo climático sazonal. A predominância de areia média pode ser explicada pela baixa energia diária de ondas, que contribui para a não remoção de partículas mais grossas, não havendo nenhum mecanismo para deposição de areia fina entre períodos de maior energia e, também, por não ocorrer ondas de swell longas, planas, que normalmente são responsáveis pelo transporte de sedimentos finos.

Texturalmente, os sedimentos superficiais do setor supramaré da praia do Farol são moderadamente selecionados e compostos por grãos angulosos. No setor intermaré a granu- lometria varia entre areia grossa a muito grossa, bem selecionada e com grãos angulosos.

O pacote sedimentar no setor supramaré apresentou comportamento homogêneo quanto as distribuição granulométrica, constituído por uma camada uniforme de areia média (Figura 7). No entanto, no setor intermaré, o pacote de areia muito grossa apresentou intercalações com níveis de areia grossa e areia média no período invernoso, tornando-se homogêneo (areia grossa) no período seco (Figuras 7 e 8).

Texturalmente a zona supramaré apresenta comportamento homogêneo em subsuperfície, sendo constituída por um pacote de areia média, moderadamente selecionada, composta por grãos angulosos. No setor intermaré, o pacote sedimentar apresenta variações granulométricas, variando de areia muito grossa a areia grossa, bem selecionada, com grãos angulosos a subangulosos. 
Figura 7- Distribuição granulométrica, grau de seleção e morfoscopia em subsuperfície nos setores supramaré e intermaré da Praia do Farol (Mosqueiro), no mês de fevereiro

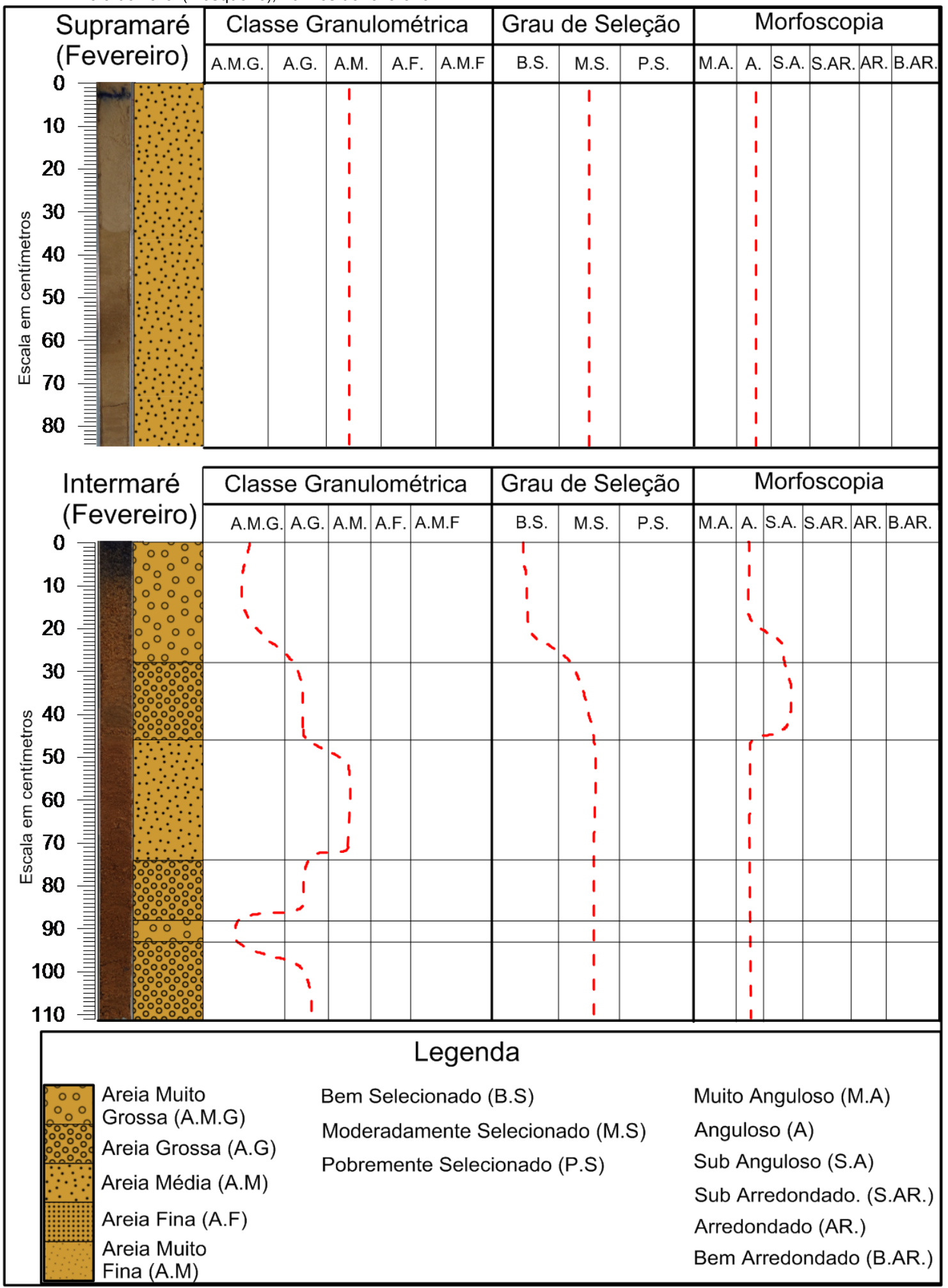


Figura 8 - Distribuição granulométrica, grau de seleção e morfoscopia em subsuperfície no setor intermaré da Praia do Farol (Mosqueiro), no mês de novembro

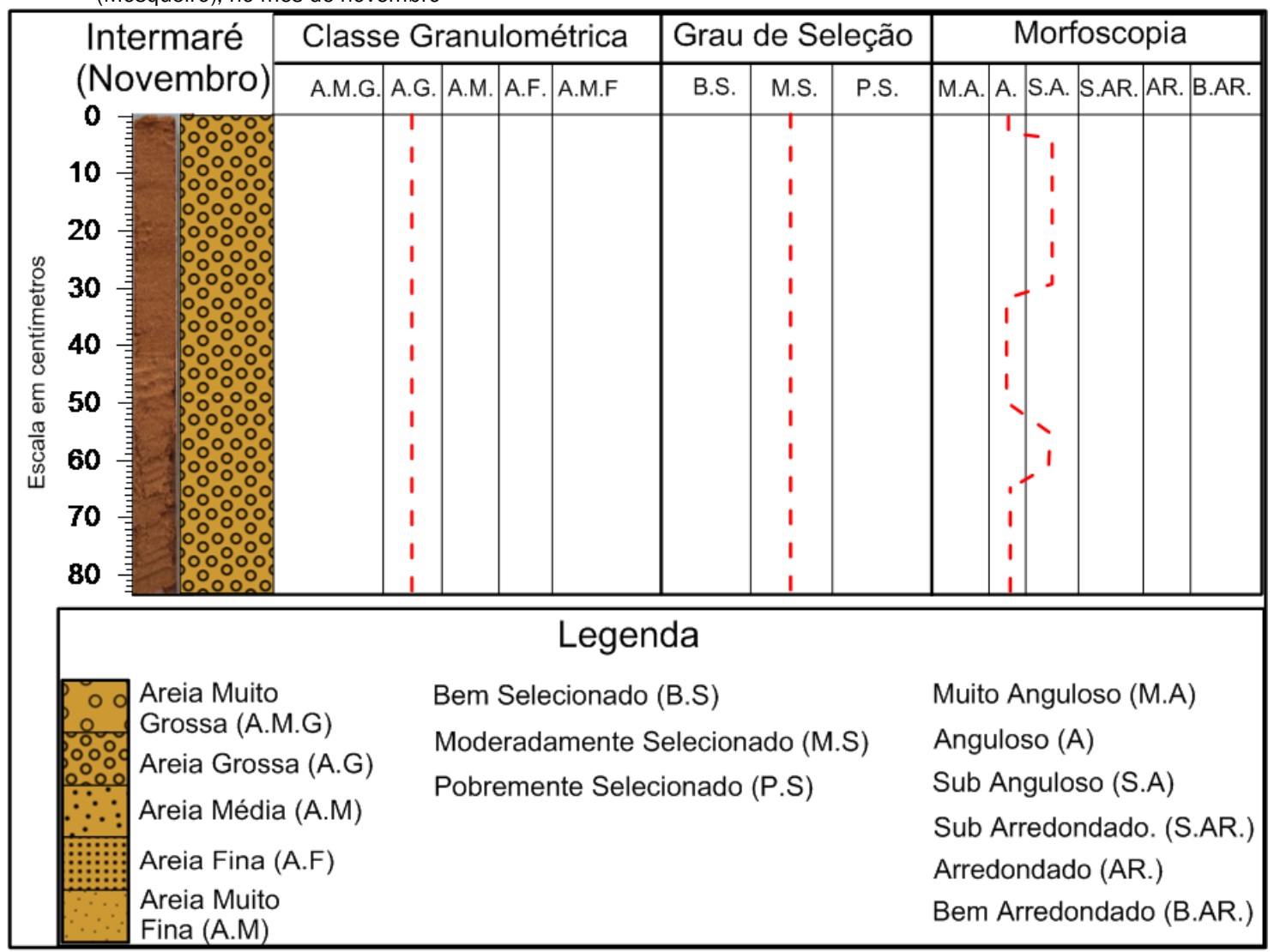

\subsection{Perfis de campo}

Os parâmetros utilizados na aquisição como o range (janela de tempo em ns), comprimento do perfil e número de amostras por scan foram escolhidos de acordo com a época do ano para cada etapa dos levantamentos, uma vez que dependiam da umidade do solo e da linha preamar máxima.

Na primeira etapa da pesquisa, em março de 2015, a linha de aquisição do perfil GPR teve um comprimento de 54 metros, com intervalo de marcação de 10 metros, com todas as medidas sendo adquiridas em linhas perpendiculares em relação à faixa de areia na direção Sul-Norte, e a janela de tempo neste levantamento foi de 100ns. É importante destacar em relação à topografia do local, que ao longo do perfil foi registrada uma forte declividade do berma em direção à linha de maré, iniciando próximo de 28 metros do início do perfil (Figura 7).

Os resultados permitiram medir a profundidade do nível freático em 1,9 metros abaixo do ponto de início do perfil
(Figura 7), e a velocidade média foi aproximadamente 0,095 $\mathrm{m} / \mathrm{ns}$ no meio saturado. Essa estimativa foi feita através da superposição de hipérbole, tomando como referência aquela destacada na parte inferior direita da Figura 5.

Na segunda etapa de campo, ocorrida em junho de 2015, foi realizado um perfil de 52 metros de extensão no mesmo ponto e com intervalo de marcação igual ao anterior, com um range de 150 ns devido a maior penetração do sinal na areia (Figura 8). Após o processamento dos dados, foi possível observar o nível freático com 2 metros de profundidade, sempre tomando como referência o ponto inicial do perfil. No radargrama ainda é possível observar o padrão hiperbólico no final do perfil destacado na figura anterior e, logo abaixo, em torno de 4 metros uma forte reflexão horizontal que pode estar associada a concreções rochosas ferruginosas encontradas no limite entre o final da Formação Pós-Barreiras e o início da Formação Barreiras na região da ilha, segundo Costa et al (1991). 
Figura 7 - Comportamento do nível freático em fevereiro de 2015, no período chuvoso, destacando a anomalia utilizada para fazer a correção de profundidade

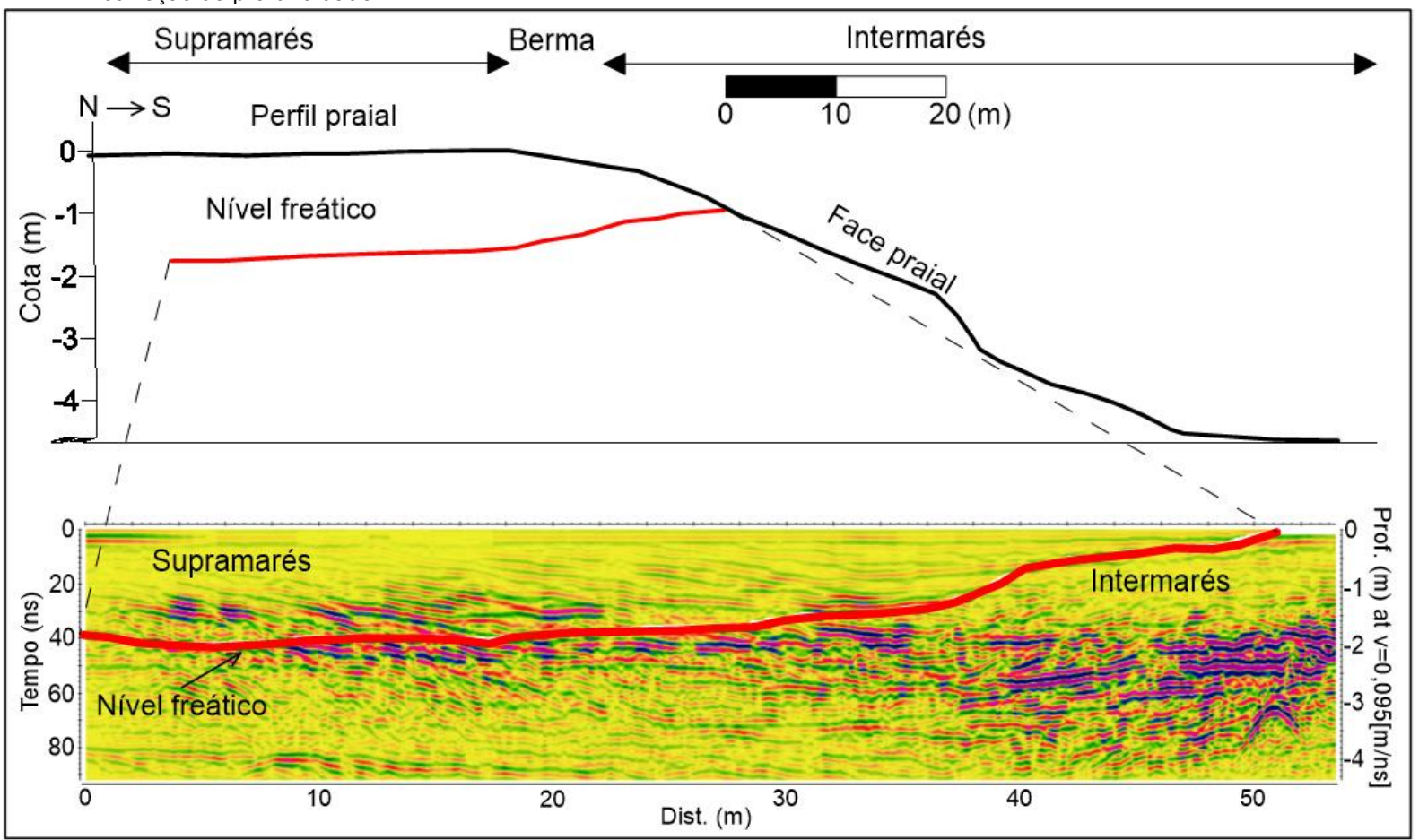

Figura 8. -Comportamento do nível freático em junho de 2015 no início do período com menos chuvas na região

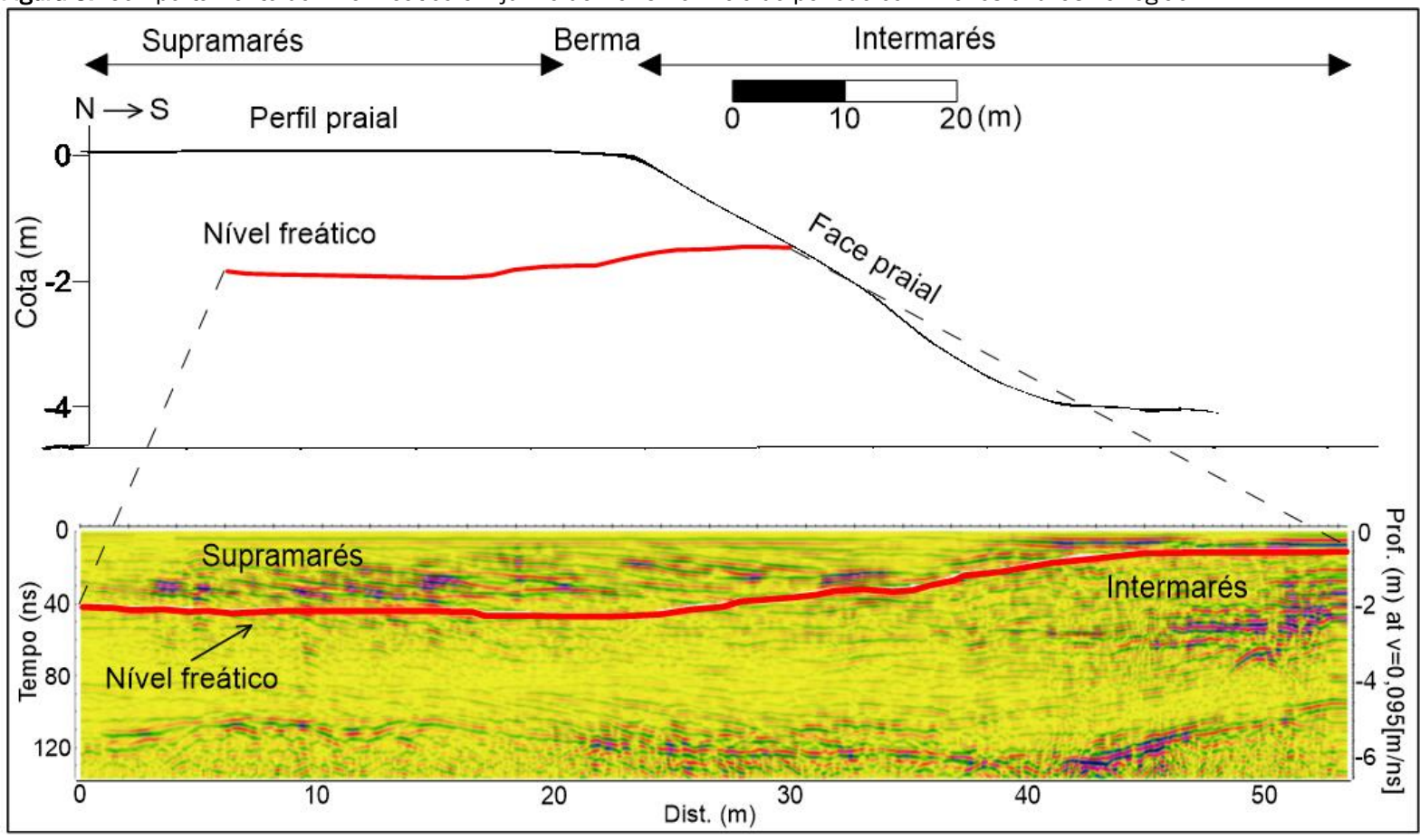

Na campanha realizada em setembro de 2015, foi realizado um perfil de 55 metros com um range de 180ns, e o resultado mostra que o nível freático encontra-se a 2 metros de profundidade (Figura 9). Foi observado também, neste perfil, que ocorreu uma zona de atenuação do sinal do GPR, possi- velmente relacionada com a presença de quantidades elevadas de sal no sedimento. No segundo semestre do ano a salinidade marinha apresentou influência maior sobre as águas fluviais devido a escassez de chuvas, influenciando fortemente os ambientes estuarinos nesta época do ano. 
Figura 9 - Comportamento do nível freático em setembro de 2015, período sazonal onde ocorre a segunda maior maré no ano

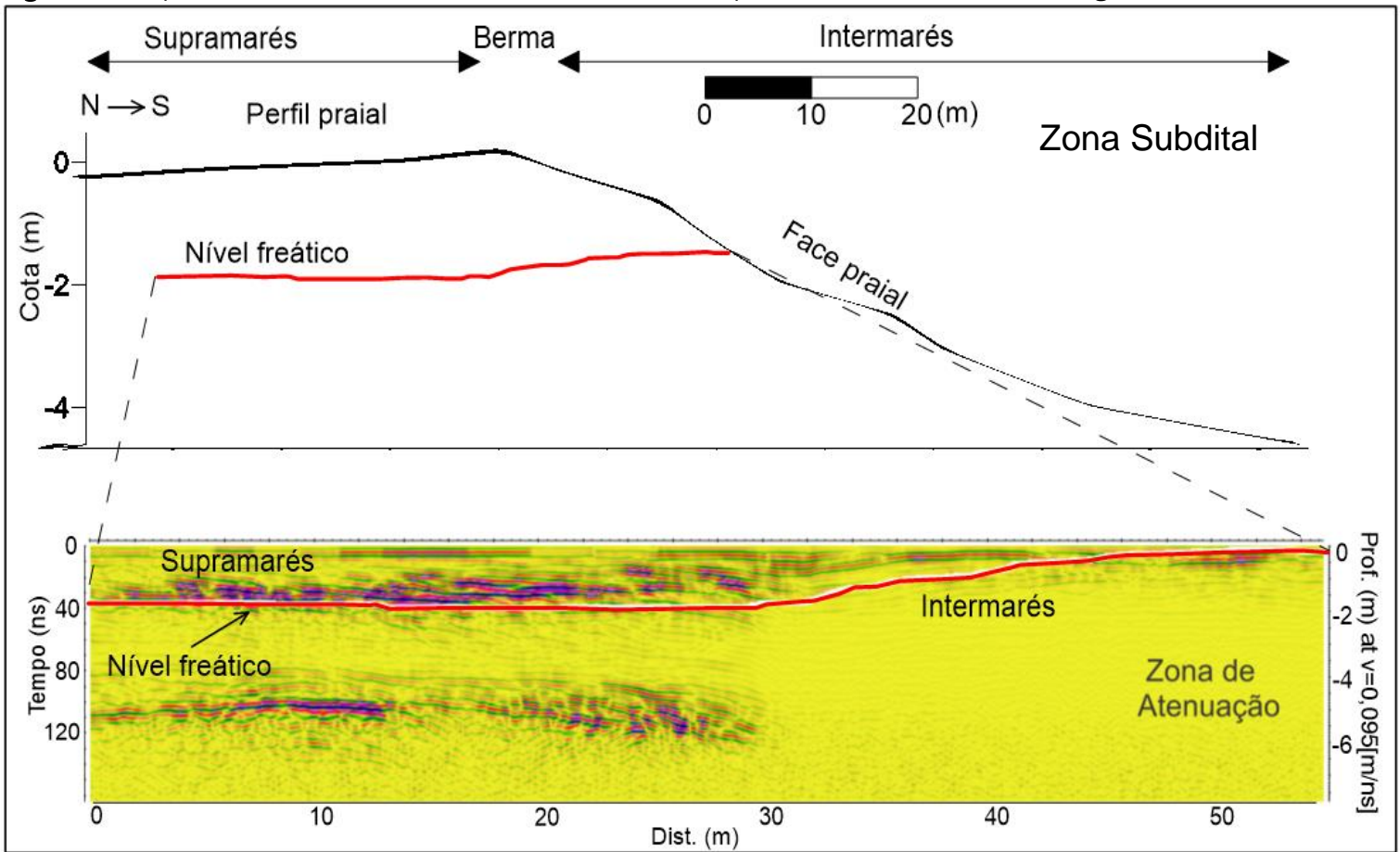

Em novembro de 2015, o perfil realizado teve 60 metros de comprimento, com um range de 180 ns, mostrando o nível freático com 2 metros de profundidade em relação ao ponto inicial do perfil (Figura 10). Os resultados mostraram novamente uma zona de atenuação a partir dos 30 metros e, ainda foi possível observar, refletores nos primeiros 30 metros com uma profundidade de 4 metros, permitindo inferir que a influência salina é reduzida nesta porção inicial do radargrama.

Figura 10 - Comportamento do nível freático em novembro de 2015, ainda no período seco na região destacando a atenuação do sinal do GPR nesta época

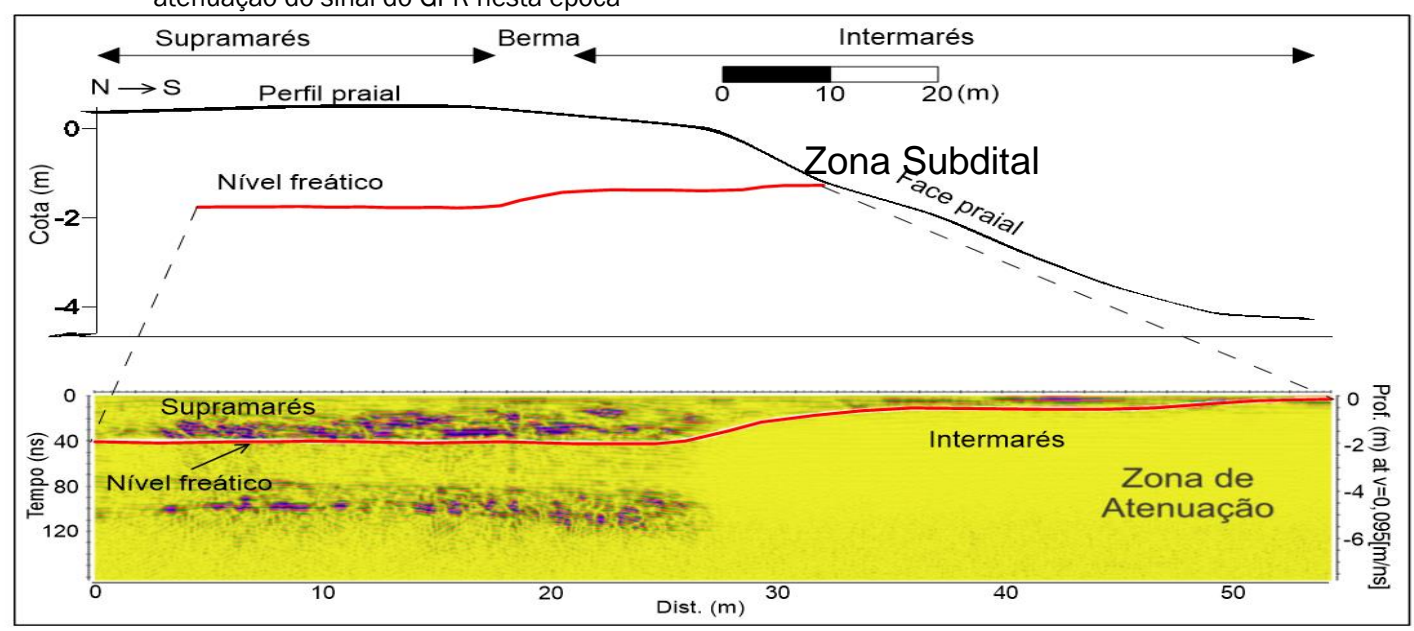

Em março de 2016, o perfil realizado com um range de 180 ns teve 40 metros de comprimento, pois com a enchente da maré, a zona de espraiamento diminui (Figura 11). 0 nível freático alcançou 1 metro de profundidade, pois durante o período mais chuvoso a água infiltra na areia e chega ao nível, aumentando seu volume e, assim, ficando mais próximo a superfície. Na Figura 9 não foi observada a zona de atenuação encontrada nos perfis anteriores, indicando que nesta época do ano a influência salina é mínima ou inexistente. No início do perfil são observadas duas interfaces horizontais distintas, com espessura média de 1,5 metros, que podem corresponder a sedimentos arenosos da Formação Pós-Barreiras e a partir de aproximadamente de 7 metros de profundidade, na faixa atenuada do sinal, infere-se podemos considerar que seja a Formação Barreiras onde é possivel encontrarmos rochas argilíticas laminadas. 
Figura 11 - Comportamento do nível freático em março de 2016, no início do período chuvoso completando o ciclo sazonal de maré

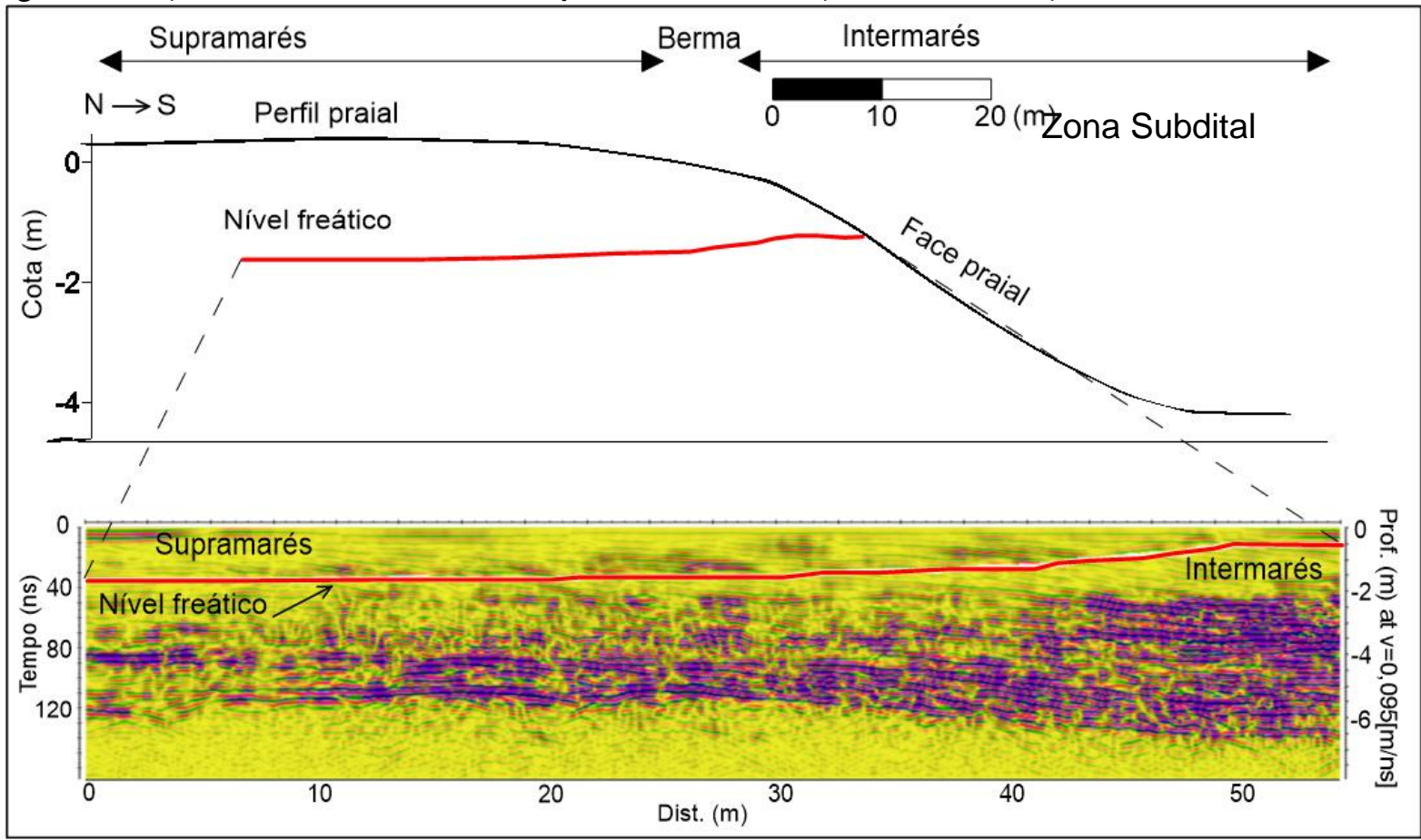

Todos os perfis coletados com o radar de penetração de solo foram correlacionados com os dados da observação sazonal do nível freático, com medições de nível em poços de abastecimento dos estabelecimentos comerciais existentes nas praias. Essas correlações e refletem perfeitamente a posição e oscilação reais do nível freático, que foram coerentes com o que os perfis de georadar mostraram nos períodos cobertos pela pesquisa.

\subsection{Modelagem Geofísica}

A modelagem eletromagnética de dados de GPR é uma ferramenta eficaz, capaz de ajudar na interpretação dos radargramas obtidos em campo. A construção de um modelo buscou simular as respostas dos dados reais, para tentar prever ou confirmar possíveis resultados de um levantamento e também pode ser usada na determinação de características eletromagnéticas que melhor se ajustam para uma possível futura aquisição de campo (Furtado, 2009).

O fenômeno em que o sinal do GPR é totalmente atenuado a partir da porção final da berma, até então, não tinha sido analisado no ambiente estuarino da Ilha de Mosqueiro. A partir de análise de dados sazonais, foi possível associá-lo à entrada da cunha salina na praia já que os perfis que apresentaram essas características foram os realizados no período com a ocorrência menor de chuvas. Para isso a modelagem geofísica foi implementada com intuito de verificar e validar esta suposição, antes baseada apenas na análise visual do radargrama.

Foi construído um modelo geológico onde foi simulada uma camada de areia seca e, a partir da fronteira Intermaré, uma faixa superficial de areia saturada com água salobra. A segunda camada também de areia saturada com água, já supondo que o nível freático esteja nela. E uma última camada com concreções ferruginosas que afloram em certos pontos da praia.

A espessura de 10 centímetros da areia salobra foi definida, pois era de interesse avaliar a menor faixa necessária para que a anomalia fosse caracterizada de acordo com o perfil adquirido no campo.

Figura 12 - Modelo Geológico baseado no dado direto obtido em campo

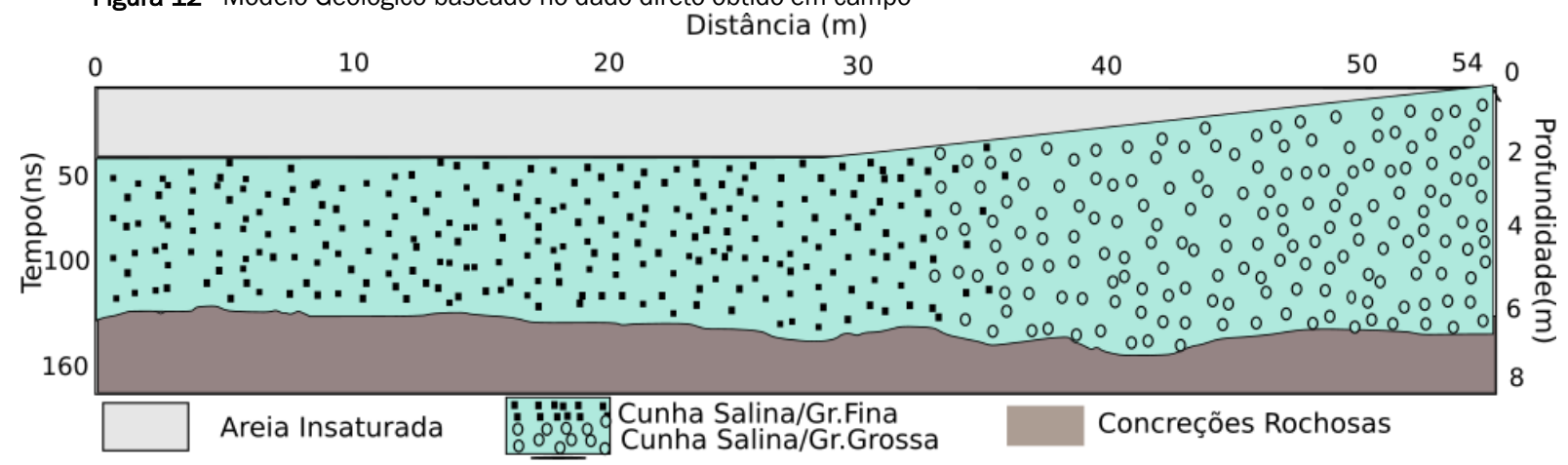


A simulação foi feita com os mesmos parâmetros utilizados em campo: a frequência de $200 \mathrm{Mhz}$, janela de tempo de $200 \mathrm{~ns}$ e a velocidade aproximada de 0,095 m/ns. As propriedades elétricas dos materiais geológicos foram obtidas através de análise de literatura.

Como o resultado das simulações, foi obtido um radargrama sintético onde é possível observar a semelhança do comportamento do sinal com o dado obtido de maneira direta no campo.

A modelagem indicou que em sistemas costeiros naturais, a extensão da intrusão de água salgada é significativamente controlada pela estratigrafia dos ambientes deposicionais. Dentre os aquíferos, aqueles dominados por ondas são mais propensos à intrusão de água salgada do que os dominados por rios e marés. A salinidade aumenta, especialmente dentro de depósitos de areia estuarinas. Simulações de atol e ilhas barreira revelam que ilhas de atóis de carbonato com unidades de alta condutividade são gravemente afetados pela elevação do nível do mar, resultando em redução significativa do volume de lente de água doce ( Swagata,2010).

A profundidade da interface é regulada principalmente pelo sistema hidrostático, balanço de água doce e água salgada, que pode ser modificada pela exploração antrópica das águas subterrâneas. Até hoje, a intrusão da água do mar é considerada um dos mais extensos e importantes processos que degradam a qualidade da água através de um aumento nos níveis de valores de salinidade (Caroti e tal,2013).

Figura 13 - Comparação entre os radargramas obtidos de maneira indireta (Modelagem) e direta (Levantamento de campo). A) Perfil Sintético obtido através da modelagem geofísica; B) Perfil adquirido em campo em novembro de 2015
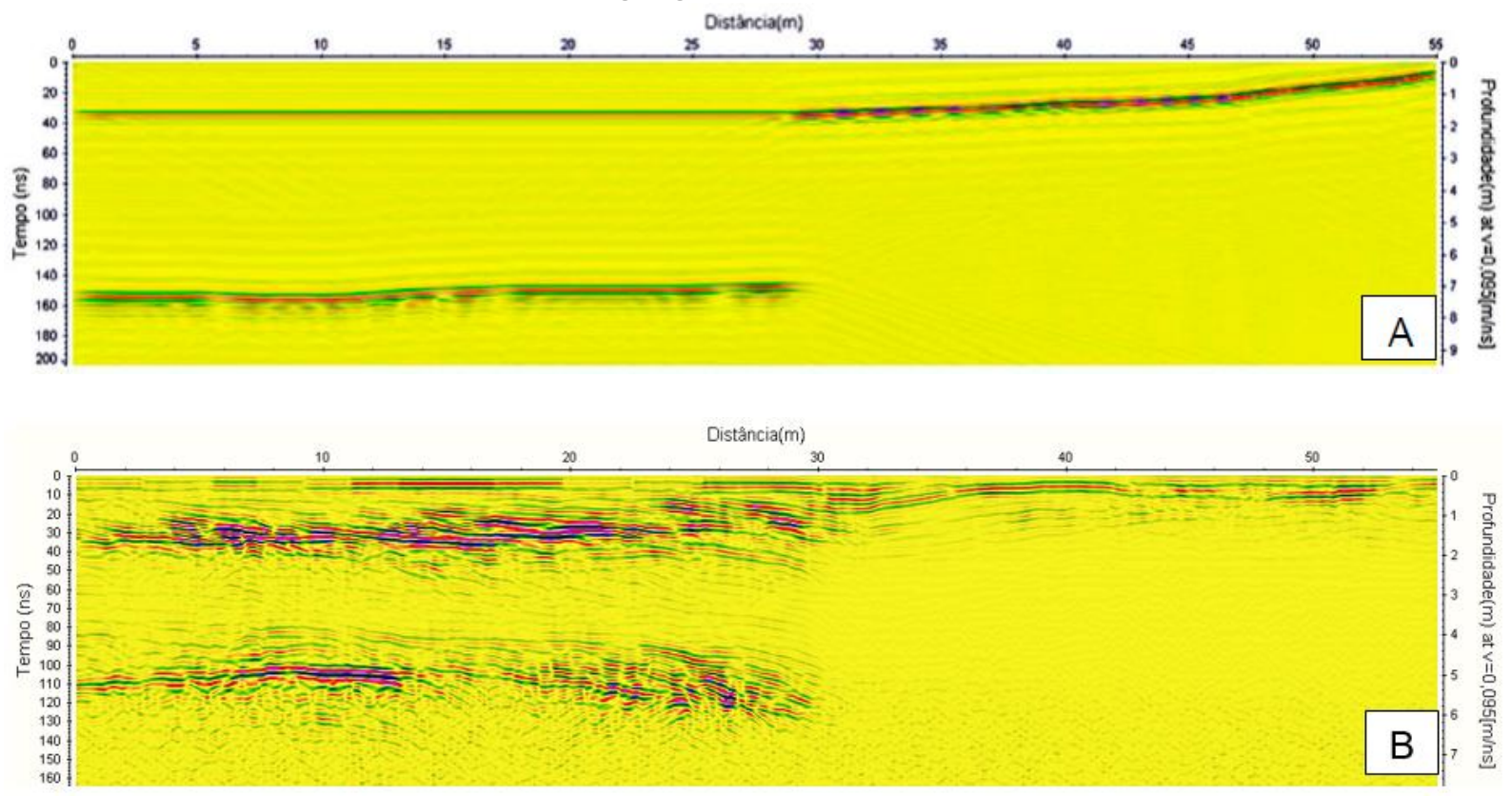

\section{CONCLUSÕES}

A alta qualidade das imagens obtidas no levantamento com o GPR, reforçam a importância que essa ferramenta geofísica possui para o delineamento da cunha salina no ambiente praial, bem como para o monitoramento do nível freático.

A identificação do nível freático foi bastante clara, revelando uma transição entre zona não saturada e zona saturada bem definida, constituindo uma franja capilar pouco espessa.

Os perfis realizados na praia do Farol (distrito de Mosqueiro) identificaram a profundidade do nível freático em todas as etapas da pesquisa. No período seco ocorre a profundidade máxima de nível freático, chegando a atingir 2 metros. Na época chuvosa o nível de profundidade máximas foi de 1 metro em relação à superfície.

Foi possível identificar a presença da intrusão da água salgada, que devido ao elevado valor de sua condutividade elétrica, causou forte atenuação da onda eletromagnética e, por este motivo, pode ser mapeada no período de estiagem.
A modelagem de dados de GPR mostrou que possivelmente o evento que ocorre na Praia do Farol nos meses com pouca chuva está relacionado com a influência da água salobra que penetra superficialmente até o limite da Intermaré.

Contudo um estudo geofísico utilizando mais métodos é recomendado para que futuramente esse tipo de fenômeno seja mais bem caracterizado no ambiente estuarino da ilha.

\section{AGRADECIMENTOS}

Ao Governo do Estado do Pará, que através da Fundação Amazônia de Amparo a Estudos e Pesquisa (FAPESPA), fomentou financeiramente $\mathrm{O}$ desenvolvimento do projeto "Permeabilidade de praias arenosas amazônicas a eventuais derrames de derivados de hidrocarbonetos" que deu suporte ao presente trabalho, assim como pela concessão da bolsa de iniciação científica.

Ao Departamento de Geofísica da Universidade Federal do Pará por ter fornecido o aparelho de GPR. 


\section{REFERÊNCIAS}

ADEOTI L, ALILE O.M. ; UCHEGBULAM, O. Geophysical investigation of saline water intrusion into freshwater aquifers: a case study of Oniru, Lagos State. Sci Res Essays v. 53, p. p. 248-259, 2010.

BRISTOW, C. S. \& JOL, H. M. (eds) Ground Penetrating Radar in Sediments. Geological Society, London, Special Publications, v. 211, p. 29-46, 2003.

COSTA, M.L.; ANGÉLICA,R.S.; AVELAR,J.O.G. Outeiro e Mosqueiro: exemplos de evolução laterítica imatura.Simpósio de Geologia da Amazônia, v.3 p.479-493, 1991.

COSTA, J.B.S; BERMEGUY,R.L; HASUI,Y.; BORGES, M.S.; FERREIRA JÚNIOR, C.R.P; BEZERRA,P.E.L; COSTA,M.L; FERNANDES,J.M.G. Neotectônica da região Amazônica: Aspectos tectônicos, geomorfológicos e deposicionais.Geonomos 4(2) 23-24p, 1996.

CPRM (Companhia de Pesquisa de Recursos Minerais). Projetos de Estudos Hidrogeológicos da Região Metropolitana de Belém e Adjacências. Belém, 2001.

DANIELS, D. J. Surface penetrating radar. Institution of Eletrical Engineers, London, p.300, 1996.

DAVIES, J. M. \& TOPPING, G. O impacto de um derrame de óleo em águas turbulentas: O Braer. Rio de Janeiro, FEMAR, 1995.

DAVIS J.L.; ANNAN A.P. Ground penetrating radar for high resolution mapping of soil and rock stratigraphy. Geophysical Prospecting, v.37, p. 531-551, 1989.

DEMIREL, Z. The history and evaluation of saltwater intrusion into a coastal aquifer in Mersin, Turkey. J Environ Manag, v. 70 , p. $275-282,2004$

ERKUL, M. HENNEBERG, D. WILKEN, M. GRÄBER, J. SCHOLTEN E W. RABBEL. Geophysical approach for mapping and quantifying near-surface freshwater-saltwater transitions. SWIM 2014 23rd Salt Water Intrusion Meeting (SWIM 2014 23rd Salt Water Intrusion Meeting. Husum, Germany, 16.06.2014).1. Edition 2014, pp108.

FURTADO. C. P. Processamento e modelagem de dados de GPR utilizando o Reflexw 4.5. Trabalho de Conclusão de Curso (Graduação) - Universidade Federal do Pará, 2009.

G.Swagata, Variable-Density Flow Models of Saltwater Intrusion in Coastal Landforms in Response to Climate Change Induced Sea Level Rise and a Chapter on Time-Frequency Analysis of Ground Penetrating Radar Signals 2010.

G. CAROTI, A. PIEMONTE, M. REDINI. The elevation net for the saltwater intrusion phenomenon analysis in the coastal plain of pisa. ISPRS International Archives of the Photogrammetry, Remote Sensing and Spatial Information Sciences, Volume XL-5/W3, p.99-105, 2013.

HAYES, M. O. \& MICHEL, J. Factors Determining the Long Term Persistence of Exxon Valdez Oil in Gravel Beaches. Marine Pollution Bulletin, v. 38 n. 2: p. 92-1001, 1999.

HODLUR GK, DHAKATE R, ANDRADE R. Correlation of vertical electrical sounding and borehole-log data for delineation of saltwater and freshwater aquifers. Geophysics 71, p. G11G20, 2006.
INMET (2015). Disponível em: http://www.inmet.gov.br/portal/index.php?r=home/page\&pa ge=rede estacoes auto graf

J. GIRAUD, M. CHOUTEAU, C. TAVEAU, R.P. CHAPUIS. Hydrogeophysical Monitoring of Groundwater Level Changes Induced by Tides in a Shallow Beach Aquifer. 17 th European Meeting of Environmental and Engineering Geophysics Leicester, UK, 12-14 September 2011.

LANI, J.L.; FRANCELINO, M.R.; ARANHA, P.; ROSADO, V.B.; VILARINHO,E. Uso de GPR na identificação da profundidade do lençol freático e na mudança textural. Anais do XXX Congresso Brasileiro de Ciência do Solo, 2005.

LEANDRO,C.G. Aplicação da análise do sinal do GPR na definição de Ambientes costeiros. Dissertação (Mestrado)- Universidade Federal Do Rio Grande Do Sul ,Instituto De Geociências, Programa De Pós-Graduação Em Geociências, 2018.

MARTÍNEZ J, BENAVENTE J, GARCÍA-ARÓSTEGUI JL, HIDALGO $M C, R E Y$ J. Contribution of electrical resistivity tomography to the study of detrital aquifers affected by seawater intrusionextrusion effects: the river Vélez delta (Vélez-Málaga, southern Spain). Eng Geol, v.108, n. 3-4, p. 161-168, 2009.

NARAYAN KA, SCHLEEBERGER C, BRISTOW KL (2007) Modelling seawater intrusion in the Burdekin Delta Irrigation Area, North Queens-land. Australia. Agric Water Manag, v. 893, p. 217-228, 2007.

PANICONI C, KHLAIFI I, LECCA G, GIACOMELLI A, TARHOUNI J. Modeling and analysis of seawater intrusion in the coastal aquifer of eastern Cap-Bon, Tunisia. Transp Porous Media v. 431, p. 3-28, 2001.

PEREIRA, A.J. A utilização do Ground Penetrating Radar (GPR) em estudos de estratigrafia na Praia de ItaipuaçuMaricá(RJ). Revista Brasileira de Geofísica, v. 21, n. 2, 2003.

PORSANI, J. L. Ground Penetrating Radar (GPR): proposta metodológica de emprego em estudos geológico-geotécnicos nas regiões de Rio Claro e Descalvado- SP. 145f. Tese (Doutorado em Geofísica) - UNESP, Instituto de Geociências e Ciências Exatas, 1999.

PRINCEWILL W IGBAGARA, IFEANYICHUKWU CLINTON EZEKWE, CHUKWUMA OJI. Hydrocarbonoclastic microorganisms and hydrocarbon pollution of groundwater in the obagi oil fields of rivers state Nigeria. TLE International Journal of Agriculture, Health and Food Sciences, v. 2, p. 12-24, 2016.

REJANI R, JHA MK, PANDA SN, MULL R. Simulation modeling for efficient groundwater management in Balasore coastal basin, India. Water Resour Manag, v. 221, p. 23-50, 2008.

Rossetti,D.P.,Late Cenozoic Sedimentary evolutionin northeastern Para,Brazil, within the contexto of sea level changes. Journal of South American Earth Sciences, v. 14, p.77-89, 2001.

Rosseti,D.P. ; Goés, A. M. ; Souza, L.S.B. Estratigrafia da sucessão Sedimentar Pós-Barreiras(zona Bragantina,Pará) com base em Radar de Penetração do solo. Brazilian Journal of Geophysics, v. 19 n.2, 2001.

Sá, J.H.S. Contribuição à geologia dos sedimentos terciários e quartenários da região Bragantina no Estado do Pará. BOLETIM GEOLÓGICO (UFRJ), v. 3 p.21-36, 1969.

SILVA, S.F. Análise Rasa de Subsuperfície com o Radar de Penetração do solo (GPR) em Depósitos neógenos na Praia do Atalaia (Salinas) e Aricuru(Maracanã),Nordeste do Estado do Pará. Trabalho de Conclusão de Curso (Graduação) Universidade Federal do Pará, 2015. 
SIVAN O, YECHIELI Y, HERUT B, LAZAR B. Geochemical Evolution and timescale of seawater intrusion into the coastal aquifer of Israel. Geochim Cosmochim Acta, v.693, p. 579592, 2005.

V. SATISH KUMAR,RATNAKAR DHAKATE,B. AMARENDER, S. SANKARAN. Application of ERT and GPR for demarcating the saline water intrusion in coastal aquifers of Southern India. Environ Earth Sci, v. 75, p. 393, 2016.

ZARROCA M, BACH J, LINARES R, PELLICER XM. Electrical methods (VES and ERT) for identifying, mapping and monitoring different saline domains in a coastal plain region (Alt Emporda, Northern Spain). J Hydrol, v. 409, v. 1-2, p. $407-$ 422, 2011. 